\title{
On the Application of Overall Cost Leadership in Coal Enterprise Technological Innovation
}

\author{
Mu Li \\ College of Humanities and Sciences of Northeast Normal University, Changchun, Jilin Province \\ 130117, China
}

254904998@qq.com

Keywords: Coal enterprises; Cost leadership strategy

\begin{abstract}
In the current revolution coal technology, coal enterprises to gain competitive advantage, the cumulative cost of the technical aspects of the value chain must be less than the cumulative cost competitors, raw materials needed in manufacturing, materials, spare parts, electricity, equipment, technological innovation, aspects of mine safety, coal washing and processing, information technology and other measures seek to reduce costs and improve the level of mine design, improve material integrated management of the electricity conducted intensive control, and establish long-term objective technical revolution, with the means of information, to gain the lead.
\end{abstract}

\section{Introduction}

Overall cost leadership refers to the main competitive means of low cost adopted by enterprises during the production to lower down the cost expenditure, it aims at increasing profits and expanding earnings for enterprises, necessary for enterprises to obtain a further development, and also the key to maintain a vantage point. With the gradual adaptation of coal enterprise technological innovation system and opinion to the technological reform under the current system of market economy, based on pursuing for scale economy, in order to strengthen the competitiveness of coal industry in the technological revolution, it is of great importance to select a proper overall cost leadership for the enterprise, adopt scientific innovation, low-cost production design, follow the path of scientific equipment and informatization, so as to spare all efforts on forming the cost advantage.

\section{The Competitive Edge of Carrying out Overall Cost Leadership by Coal Enterprises}

First of all, although the shale gas development technology has been widely applied in recent years, the prices of petroleum and natural gas are further dropping, the replaceability of coal resources is enhancing. However, in the following period, coal is still the main demanded energy in China, and occupies a high market share in energy production and consumption structure. Secondly, according to the national macro-control, the small-scale coal mines are gradually closed. The coal production of existing coal enterprises owns a certain scale and abundance of capital, so the unit cost is gradually decreasing. Thirdly, as the scientific technology develops, the coal enterprise has also imported a great amount of advanced equipment, turned the previous construction technology of intensive manual excavation and exploitation into fully-mechanized coal mining and fully-mechanized excavation technology, the application of some top technology is widespread, so the productive efficiency of coal enterprises has been improved and the cost of products is lowered. Fourthly, in spite of the dominant product- coal, some auxiliary materials used for coal mining can be repeatedly recycled and reused, the advantage of integrated resources in strong and convenient for saving the cost of raw materials. Fifthly, the coal enterprise belongs to undermining industry, which has an organization structure with clear responsibilities for an efficient control over all expense. 


\section{Competitive Disadvantages of Carrying out Overall Cost Leadership by Coal Enterprises}

Firstly, unlike the general industrial production, coal production is greatly affected by geological structure, storage and reserve and natural conditions. The expense of exploration, planning and designing is great. Then, coal production has frequently been threatened by natural conditions like water, fire, gas, fault, coal dust, and a certain of manpower and material resources shall be invested in ventilation, drainage, fire protection, lighting, dust prevention and so on. Secondly, coal mining enterprise belongs to undermining industry, in order to maintain the normal operation of production, some auxiliary materials like wood, support materials, belt, power and detonator should be invested, so the cost may be relatively high. Thirdly, although the mechanization degree of coal mining has been somewhat improved in recent years, a great amount of underground operation has determined coal industry as the labor-intensive industry. Meanwhile, as the requirement for access to miners is low, the working environment is tough, the working places are scattered, the labor intensity is great, and the possibility of inflicting with occupational diseases or encountering risks grows, subsequently, the value compensation of various kinds of labor, protection medicine supply and high-risk operation allowance are objectively higher than other industries, so the proportion of wage cost is heavy. Fourthly, the segregation between technology and economy. For example, coal mining enterprises are mostly engaged in both excavation and exploitation, most of its expense is burdened by production cost, which has occupied $20 \%$ of the total direct expense. Besides, the exploitation difficulty, technical process, and coal resources use ratio has been largely affected by geographical condition and construction, the repair and renewal cost of large mechanized equipment is relatively high, and the backward technique has hindered the improvement of resource usage. Fifthly, along with the widespread application of modern technology, electricity has become the main power of coal production. From 2001 to 2005, the percentage of coal cost growth has risen from 100\% to $145 \%$, the electricity cost has upsurged from $100 \%$ to $164 \%$, and the electricity improvement has exceeded $10 \%$ of coal cost. Lastly, even though the coal enterprise has already constructed cost accounting and simple cost analysis, but the informatization degree is not high, the information feedback is slow, and there are no scientific prediction, accounting, analysis, control and decision-making based on market information and enterprise condition. Therefore, the adverse variance has not been timely processed by taking effective measures, and the enterprise has not set up a set of accounting mechanism about cost responsibility. As a result, the responsibility is not clear, accounting is uncertain, and the cost of raw coat becomes distorted and uncontrolled.

\section{The Application of Overall Cost Leadership in Coal Industry Technological Innovation}

In order to acquire the competitive advantage, coal enterprises need to keep the accumulative cost on the technical aspect of value chain lower than that of its rival, there are the following methods for realizing: one is to improve the design level of mine and implement scale economy, then it's necessary to well manage all materials and reduce unnecessary waste and loss. Thirdly, the electricity cost needs to be intensively controlled, and electricity utilization needs to be scientifically controlled. Fourthly, the enterprise has to set a long-term goal and develop the technological revolution. Fifthly, it requires to improve the cost structure for enterprise by adopting informatization means.

Improve the Design Level of Mine, and Decrease the Cost of Exploiting Raw Coal. In the first place, the main production condition of coal enterprise is coal resources, level continuation has an innate decisive role. In order to decrease the cost of raw mine after production, it's necessary to adhere to the principle of technical advancement and economic rationality in mine designing. Based on the indispensable geological exploration of complicated geological structure, a prediction on the investment profit of coal reserve will be carried out, after repeatedly verifying the feasibility research, the final development and design program with the advanced technology, rational layout and maximum economic profit will be selected for mine construction. Then, during construction, coal enterprises can organized excavation teams to excavate roadway, discuss on coal excavation program, formulate mining measures, slow down 10000-ton tunneling rate, so as to reduce the 
related expense; by paving tunnels and erecting stringing, the ground construction expense can be decreased. What's more, enterprises can also adopt the drilling-blasting method to enlarge to the design section, eventually, the usage of slip form to concrete supports can bring about an actual effect of small investment and securer outcome. Thirdly, according to the principle of economics, before achieving a certain scale, as the production of a product grows, its cost will decrease. By expanding the production and accelerating a scientific adjustment of the coal structure of self-produced products, enterprises can reach a decrease in the cost of raw coal. Upon the massive production, enterprises will easily obtain the price advantage in raw materials, energy and spare parts and then form a stable cooperative relation with upstream suppliers, as the tangible cost decrease, the intangible cost will drop, so as to further reduce the overall cost of raw coal.

Well Prepare for the Control of Comprehensive Materials, and Reduce Unnecessary Waste Loss. In recent years, the necessary materials needed by coal mine greatly fluctuate in price, and coal mine materials don't consist of the product entity, so the cost composition of coal mine enterprise is greatly influenced. Therefore, there is a necessity to strengthen the integrated control of expenses produced by materials and accessories and then reduce the materials expense. First of all, as for the high-value, intensively-used, easily-recycled and repairable large-scale materials and accessories like mine supporting timber, mine supporting devices, pyrotechnic device, supporting devices, rolled steel, shed, water tube, related wire mesh, carrier roller, chain, belt conveyor, conveyor, scraper-trough conveyor, top, unit motor and pump, the concentrated management is adopted, materials will be settled according to the schedule, and approved large-scale materials will be followed and assessed by specially-assigned people, like strictly arranging for the supporting forms, sections, coal rock, tunnel maintenance which are used in tunneling continuation sites, and assigning each item of cost quota and responsibilities on the head of coal mine, and heads of divisions of coal mining, tunneling, transporting, electromechanics and ventilation. Secondly, as for untraceable and unrecoverable general materials of diversified varieties and low unit values like metal net, plastic net, wire-rope, gasket, miner lamp, signal wire and each types of switches, components, small equipment and installation materials, quantitative distribution, contracted management, field supervision, mechanism assessment are adopted to reduce unnecessary waste or loss. Meanwhile, efforts should be put on making an inventory and having a classification collection of old steel chisels, broken cable and overstocked tool and materials, and also exploiting potentiality in repair the old and utilize the waste . Besides, as shown in Fig. 1, equipment engineering plan will be well organized. 


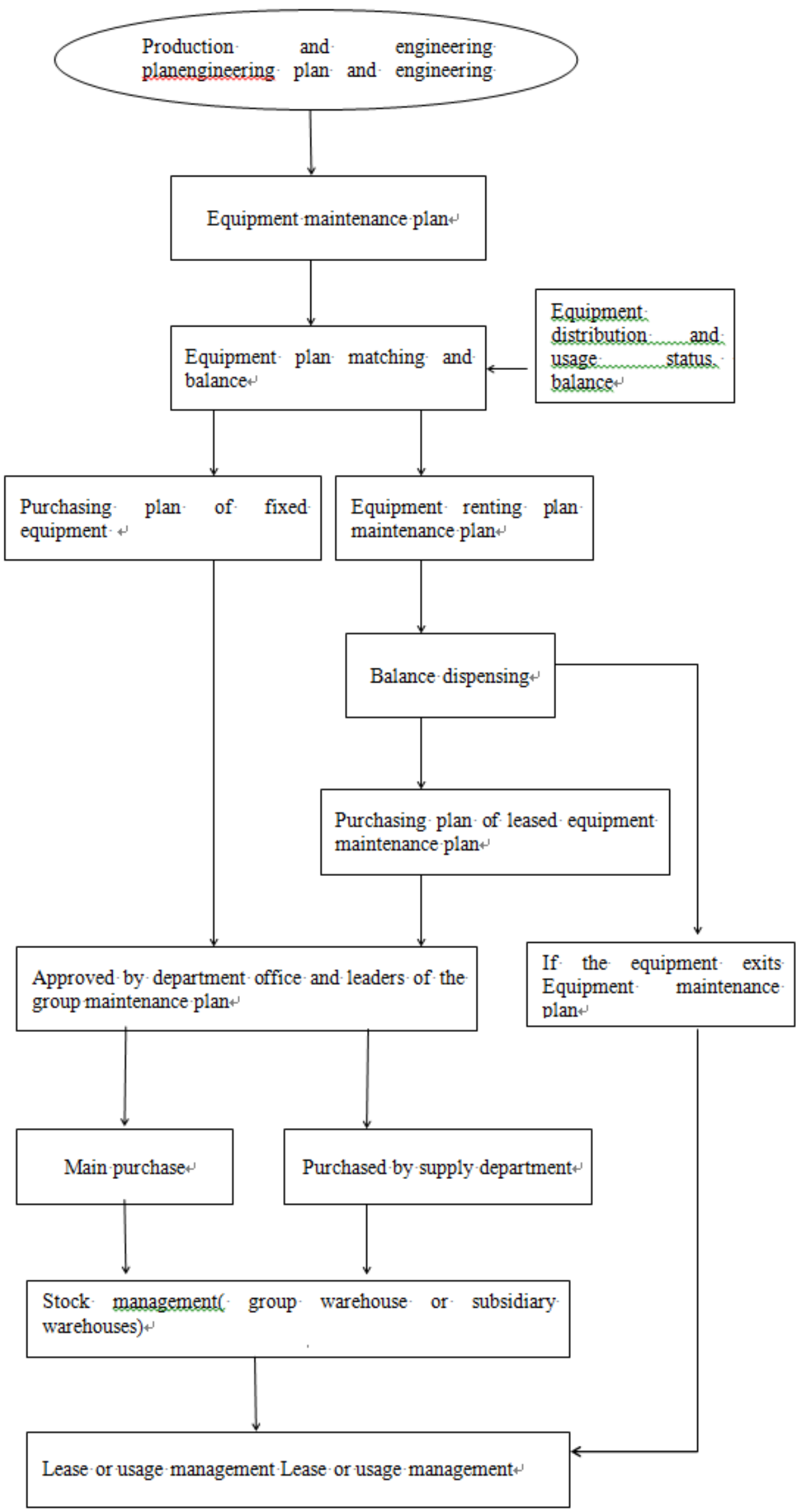

Figure 1. Flow diagram of equipment plan management 
Intensively Control over Electricity Rate, and Scientifically and Rationally use Electricity. Coal production is based on electric power, devices like ventilation, drainage, air compression and promotion will only be maintained by electric energy. Through the analysis of the relation between coal cost and electricity rate, in recent 5 years, as the coal enterprises are adopting modern methods of exploitation, the proportion of electricity rate in cost is gradually enhancing, it has become the common problem for each coal enterprise operator to consider how to control the electricity rate expense, reduce cost and promote benefits. The first thing falls on perfecting energy measurement device. It's required to replace and renovate the ground power supply system and install electricity meters in different areas of mine. Besides, power utilization index shall be set and related measure and plan should be formulated. Secondly, it comes to the rational power utilization. As for power-consuming equipment of reducing peak load like drainage, waste rock hoist, pressure fan, winch, it's necessary to confirm the available machine time, adjust power consumption range, reduce the peak load and realize peak cut based on production features and time. Thirdly, the enterprise needs to save electricity consumption in accordance with production demand, such as calculating blowing rate required by mine and adopting air-foil fan for driving face, besides, according to the change of ventilation distance, it's necessary to momentarily adjust the model selection of fan, the angle of fan blade, strengthen the technological transformation of strong current control, improve the performance of ventilation system, reduce tunnel air leakage and save electricity consumption. Meanwhile, coal enterprises still need to intensify power utilization analysis, carry out technological reform and innovation of unit with small unit capacity and high coal consumption rate, apply underground electricity telemetry, remote communication and remote control system, dual ventilator, underground water drainage and supply telemetry, remote communication and remote control system to have dynamic control, and then timely find out excess and effectively process with it.

Table 1 Relation between coal cost and electricity rate from 2011 to 2015 Unit: yuan/ton

\begin{tabular}{|l|l|l|l|l|l|}
\hline Year & Coal cost & $\begin{array}{l}\text { Electricity } \\
\text { rate }\end{array}$ & $\begin{array}{l}\text { The } \\
\text { proportion of } \\
\text { electricity } \\
\text { rate in cost } \\
(\%)\end{array}$ & $\begin{array}{l}\text { Increase of } \\
\text { coal cost }(\%)\end{array}$ & $\begin{array}{l}\text { Increase of } \\
\text { electricity rate } \\
(\%)\end{array}$ \\
\hline 2011 & 188.43 & 4.02 & 2.13 & 100.00 & 100.00 \\
\hline 2012 & 194.98 & 4.53 & 2.32 & 103.54 & 112.69 \\
\hline 2013 & 200.06 & 4.77 & 2.38 & 105.43 & 118.66 \\
\hline 2014 & 224.48 & 5.93 & 2.64 & 118.57 & 147.51 \\
\hline 2015 & 275.02 & 6.61 & 2.40 & 145.50 & 164.43 \\
\hline
\end{tabular}

Set a Long-term Goal, Carefully Carry out Technological Revolution. Technological control is the origin of cost control, technological revolution is the everlasting truth for enterprises to lower down cost and win by a surprise action, which may greatly reduce the cost and bring about the efficiency improvement of production organization. As a result, in order to effectively reduce cost, coal enterprises need to promote technological content, set up long-term goals, change the previous routines of sole focus on cost control and post-action control and negligence about technological investment. In a short period, although the technological innovation and introduction will increase expenditure, it may also promote the working efficiency and utilization life of equipment, basically abandon production parts which largely waste manpower, financial resources and material resources, and save cost and promote the economic benefits of enterprises. Based on the world's coal mining technology, Chinese coal enterprises need to improve and innovate their own production technique and technology, and then expand technological investment according to their own geological condition and natural resources, like changing the traditional production technique, optimizing design and model selection, choosing technologically advanced, excellently 
performed equipment for mining, excavation, transportation and installation, enhancing the efficiency of mining technological system and improving producing capacity of coal working face; adopting continuous mining tunneling technology to ensure the rapid tunneling and growth of mine yield; by applying advanced devices trackless belt conveyor, computerized washing apparatus, rapid loading system to implement matched integration; realizing the integrated automation of well, selecting automatic industrial controlling products like fully mechanized working face, well industrial television system, underground air door automatic control system, belt transporting automatic system, axle temperature detection system, production scheduling, and improving the coordinated operation integration level among various equipment systems to conduct real-time operation supervision, real-time process control, equipment fault alarm, production scheduling optimization, so as to promote the working efficiency of mining, decrease the cost of post production and boost the production capacity of coal.

Improve Cost Structure with the Help of Informatization Means. As the information technology gradually imposes an overall influence on the value chain, enterprises can not only realized highly efficient automatic production system with the help of information technology, but also optimize the business procedure to perfect the cost structure and lower down enterprise cost. For examples, e-commerce can speedily acquire market information, accurately implement product positioning, avoid the harm of information isolated island on the business development of enterprises, besides, it can significantly reduce the transaction expense; the construction of local area network of mine can solve the problems of distant distribution of coal mining areas and low-efficient contact, more importantly, it can directly bear some key businesses like coal production scheduling, gas supervision, security management of underground and fan supervision; EAM system and MIS accessory supply management system based on information asset management can record the data information of the whole process of equipment, including equipment technological information, financial information, maintenance depreciation, operational calender and so on, it can realize functions of material spare parts like storage and delivery, automatic inventory accounting and dynamic adjustment, through the statistical analysis, the consumption quota can be compiled, and the preventive, accurate and economic accessory ledger can be generated.

\section{Conclusion}

It is the necessity for coal enterprises to carry out overall cost leadership so as to reform traditional cost management and adapt to market economy survival and development requirements5, its effect directly determines the implementation effect of enterprise strategy. At current, difficulties like inconsistent informatization standard, scarcity of technological experts and capital collection are existing during the process of carrying out overall cost leadership, so coal enterprises need to give a comprehensive consideration on cost structure, development and utilization of talents and resources, introduction of technology and formation of profits, insist on promoting reform to enhance the competitiveness of coal enterprise market and realize leapfrog development.

\section{Reference}

[1] Feng Xinjun, Lv Hongxia, Discuss on the Application of Overall Cost Leadership in Coal Enterprises(J), Coal Engineering, 2007, (12):115-116.

[2] Wang Yun, Wang Yunzhu, SWOT-Based Research on Coal Enterprise Strategical Transition(J), Contemporary Economy \& Management, 2012(2).

[3] Li Shaowang, A Brief Discussion on the Application of Strategical Cost Management in Coal Enterprises(J), Value Engineering, 2011:110.

[4] Zhang Jinxin, Research on the Strategic Cost Management of Coal Enterprises(J), China Economist, 2011(10): 168-169

[5] Wang Shengjiao, Research on the Strategic Cost Management System Design of Coal Enterprises(J), Coal Enterprise Management, 2014(2):46-47

[6] Li Sheng, Analysis of the Strategic Cost Management of Coal Enterprises(J), Coal Technology, 2013.01. 